\title{
Consultation rates among middle aged men in general practice over three years
}

\author{
D G Cook, J K Morris, M Walker, A G Shaper
}

\begin{abstract}
Objective-To provide data on consultation rates in general practice for middle aged men over three years according to their age and social class.

Design-Prospective study of men over eight years. Data on consultation rates during years 6-8 were collected retrospectively from practice records.

Setting-Over 1000 general practices in Great Britain by year 8. Initially (in 1978-80) the men had been selected at random from one practice in each of 24 towns.
\end{abstract}

Subjects -7013 Men aged 46-65 in the sixth year of follow up.

Main outcome measure-Number of consultations a year over three years.

Results - The mean annual consultation rate over the three years rose steadily with age (7.0 at age 46-50 to 9.7 at age 61-65) and with social class (6.4 in class $I$ to 10.0 in class $\mathrm{V}$ ) but was potentially misleading as the distribution was skew: $10 \cdot 5 \%$ of men (736) did not consult over the three years and $17 \cdot 2 \%$ (1209) consulted only once or twice, whereas $11.4 \%$ (798) of men were seen more than 18 times. The percentage of men who did not consult over three years fell only slightly with age and was unrelated to social class, with roughly a tenth of all age and social class groups not consulting. Two thirds of non-consulters in year $6(1598 / 2334)$ consulted in year 7 or 8 .

Conclusions-The mean is not an appropriate summary measure of consultation rates and may conceal important differences among practices or other groups. The new general practitioner contract stipulates that all patients aged 16-74 must be provided with information to promote health and prevent illness at least once every three years. Most practices will have to approach a tenth of their men aged 46-65 specially to provide this service even if one consultation in three years is regarded as sufficient to allow a service to be provided.

\section{Introduction}

The 1990 general practitioner's contract stipulates that information on promoting health and preventing illness must be provided to patients aged 16-74 during a consultation or at a clinic at least once in three years.' Those patients not seen must be specially invited to attend. Thus there is an overwhelming need to know about patterns of consultations over three years.

In the past consultation rates have been summarised either as the average annual consultation rate ${ }^{2}$ or as the proportion of patients consulting in the past 14 days. ${ }^{3}$ Unfortunately, the number of consultations with a general practitioner over one year varies strikingly between people and the distribution is highly skew, with many people seeing their doctor only rarely and a few seeing their doctor many times. The above two summary measures are thus poor indicators to use when studying those who consult rarely or when comparing groups. Moreover, because a person's consultation pattern is not independent from one year to the next information about this dependency is necessary to predict what proportion of patients will not consult over three years from a single year's data such as those available from the Royal College of General Practitioners' national morbidity survey.

We examined the consultation rates of 7013 middle aged British men over three years to ascertain whether previously used measures are good summary statistics and, if they are not, to suggest more relevant ways of presenting the data. We looked at the patterns of consultation and analysed the data by age and social class.

\section{Subjects and methods}

During 1978-80, 7735 men aged 40-59 were selected at random from one general practice in each of 24 British towns for a prospective study of cardiovascular disease (the British regional heart study). ${ }^{4}$ After eight years the current general practitioners of the surviving men were asked to complete a form recording the number of times each man had consulted in each year of the eight year follow up. A consultation was defined as any recording in the patient's medical notes with a date. Notes were not available for 545 men who had died before the end of the eight year follow up period and 51 who had emigrated. Data on 126 men were incomplete, and the reasons for this varied: six men could not be traced, and others had had their notes summarised or had been out of the country for part of the time. Thus complete data were available for 7013 $(98 \cdot 2 \%)$ of the 7139 men who were alive and had not emigrated.

Social class was determined from each man's longest held occupation by using the six social classes of the Office of Population Censuses and Surveys. ${ }^{5}$ Sixteen men whose longest held occupation was in one of the armed services were excluded from the analysis.

We report here the data for years 6-8 of the study. There were three reasons for this choice: firstly, we concentrated on a three year period for each man as this is central to the general practitioner's contract; secondly, these were the most recent data we had (relating to 1984-8); and, thirdly, any bias due to selection of healthy subjects at the start of the study was considerably reduced.

Throughout this paper we refer to the age of the men at the beginning of the three years - that is, in the sixth year of follow up, when the men were aged 46-65. By the eighth year of the study roughly 1000 men had changed their practice at least once.

\section{Results}

NUMBER OF CONSULTATIONS DURING EIGHTH YEAR OF STUDY

Figure 1 shows the distribution of the number of 


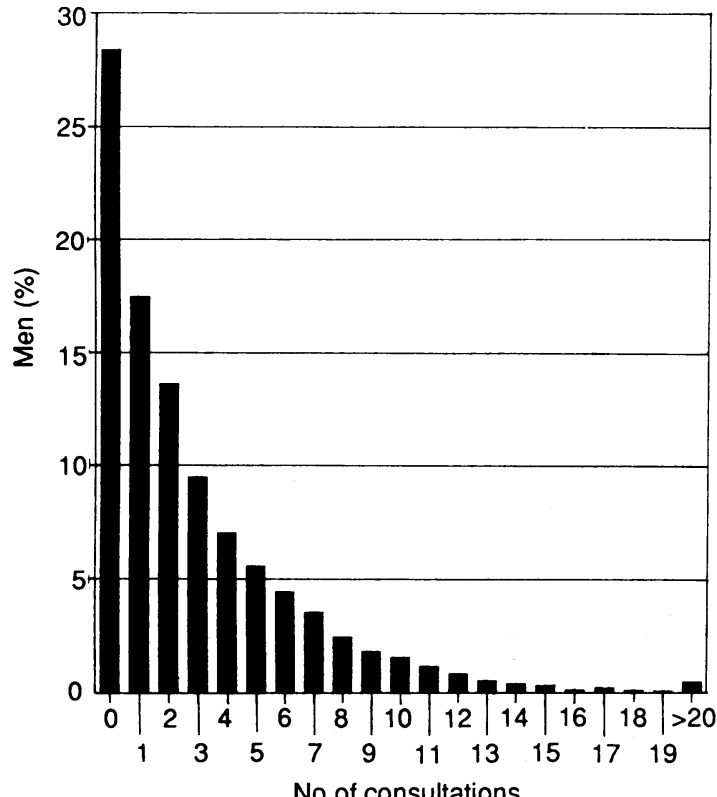

FIG 1-Distribution of number of consultations for 7013 men in year 8 of the study

consultations for the 7013 men during the eighth year of the study. The average number of consultations was 3.0 (SD 3.8); 4176 men consulted less often than this, and only 2170 consulted more than this. Clearly the mean was not a good summary measure. A far better measure was the percentage of men who consulted 0,1 or 2, 3-6 and $\geqslant 7$ times a year (non-, low, moderate, and high consulters respectively). This is because 4176 men $(59 \cdot 5 \%)$ consulted $0-2$ times in year 8 but accounted for only $15 \cdot 0 \%(3139 / 20967)$ of the total consultations while almost half $(10024 / 20967)$ of all consultations arose from the $973(13.9 \%)$ men who consulted $\geqslant 7$ times in year 8 .

\section{NON-INDEPENDENCE OF CONSULTATION RATES FROM} YEAR TO YEAR

Table I shows the distribution of consultation rates in year 6 related to the subsequent consultation rate in years 7 and 8 . Non-consulters in year 6 were the group most likely to be non-consulters and least likely to be heavy consulters in years 7 and 8 . Conversely, high consulters in year 6 were likely to be high consulters in years 7 and 8 and were unlikely not to consult. Moreover, low and medium consulters in year 6 were likely to be low and medium consulters in years 7 and 8 . Thus knowing the number of times a man consults in one year permits a prediction of how often he will consult over the next two years.

The importance of this information is shown in table II, where the observed number of years (of three) in which a man was seen by his general practitioner is compared with the number estimated by assuming that each year was independent (that is, no correlation between successive years). Table II shows that the number of men not seen by their general practitioner over the three years was more than three times the expected number. At the other extreme the number seen in all three years was also greater than the

TABLE I-Number of consultations by men in year 6 compared with years 7 and 8. Figures are numbers (percentages) of men

\begin{tabular}{lccrcc}
\hline & & \multicolumn{4}{c}{ No of consultations in years 7 and 8} \\
\cline { 3 - 6 } $\begin{array}{l}\text { No of consultations } \\
\text { in year 6 }\end{array}$ & No of men & 0 & $1-4$ & $5-12$ & $\geqslant 13$ \\
\hline 0 & 2334 & $736(31 \cdot 5)$ & $1123(48 \cdot 1)$ & $404(17 \cdot 3)$ & $71(3 \cdot 0)$ \\
1,2 & 2221 & $288(13 \cdot 0)$ & $1075(48 \cdot 4)$ & $718(32 \cdot 3)$ & $140(6 \cdot 3)$ \\
$3-6$ & 1672 & $87(5 \cdot 2)$ & $498(29 \cdot 8)$ & $792(47 \cdot 4)$ & $295(17 \cdot 6)$ \\
$\geqslant 7$ & 786 & $15(1 \cdot 9)$ & $88(11 \cdot 2)$ & $292(37 \cdot 2)$ & $391(49 \cdot 7)$ \\
\hline Total & 7013 & $1126(16 \cdot 1)$ & $2784(39 \cdot 7)$ & $2206(31 \cdot 5)$ & $897(12 \cdot 8)$ \\
\hline
\end{tabular}

expected number. This is what we would expect. Overall, $1126(16 \cdot 1 \%)$ men were not seen in years 7 and 8 . Thus if consultation patterns in years 7 and 8 had been independent of those in year 6 we would have expected $16 \cdot 1 \%$ of non-consulters in year 6 not to be seen over the next two years. In fact $31 \cdot 5 \%(736 / 2334)$ were not seen because non-consulters tended to remain non-consulters. A similar argument held for heavy consulters.

DISTRIBUTION OF CONSULTATIONS OVER THREE YEARS

Figure 2 shows the distribution of consultations over three years (years 6-8 of the study). Altogether 736 men were not seen by their general practitioner over the three years. A further 1209 were seen only once or twice. At the other extreme 798 were seen more than 18 times.

\section{DIFFERENCES IN CONSULTATION RATES WITH AGE}

The mean consultation rate each year over the three years rose with age, being $7 \cdot 0,8 \cdot 0,9 \cdot 0$, and $9 \cdot 7$ for the age groups 46-50, 51-55, 56-60, and 61-65. To compare the consultation rates by age in further detail we divided the distribution of the number of consultations over the three years: $0,1-6,7-18$, and $\geqslant 19$ consultations (table III). The proportion of men not seen over the three years fell only slightly with age from $11 \cdot 4 \%$ at ages $46-50$ to $9 \cdot 4 \%$ at ages $61-65\left(\chi^{2}\right.$ for trend $=5 \cdot 99$, $\mathrm{p}=0.014)$. In contrast, the proportion of men consulting $\geqslant 19$ times rose from $7 \cdot 4 \%$ at ages $46-50$ to $14 \cdot 8 \%$ at ages $61-65\left(\chi^{2}\right.$ for trend $\left.=54.55, p<0.0001\right)$. Thus though consultation rates clearly rose with age, there appeared to be a group of confirmed non-consulters of similar size in each age group.

DIFFERENCES IN CONSULTATION RATES WITH SOCIAL CLASS

The mean consultation rate each year over the three years rose steadily from social class I to $\mathrm{V}$, being $6 \cdot 4$,

TABLE II-Number of years in which men consulted their general practitioner. Figures are actual numbers (percentages) of men and numbers (percentages) estimated by assuming that each year was independent

\begin{tabular}{lcc}
\hline No of years & Observed No (\%) & Estimated No (\%) \\
\hline 0 & $736(10 \cdot 5)$ & $206(2 \cdot 9)$ \\
1 & $1268(18 \cdot 1)$ & $1388(19 \cdot 8)$ \\
2 & $1757(25 \cdot 1)$ & $3108(44 \cdot 3)$ \\
3 & $3252(46 \cdot 4)$ & $2311(33 \cdot 0)$ \\
\hline Total & $7013(100 \cdot 0)$ & $7013(100 \cdot 0)$
\end{tabular}

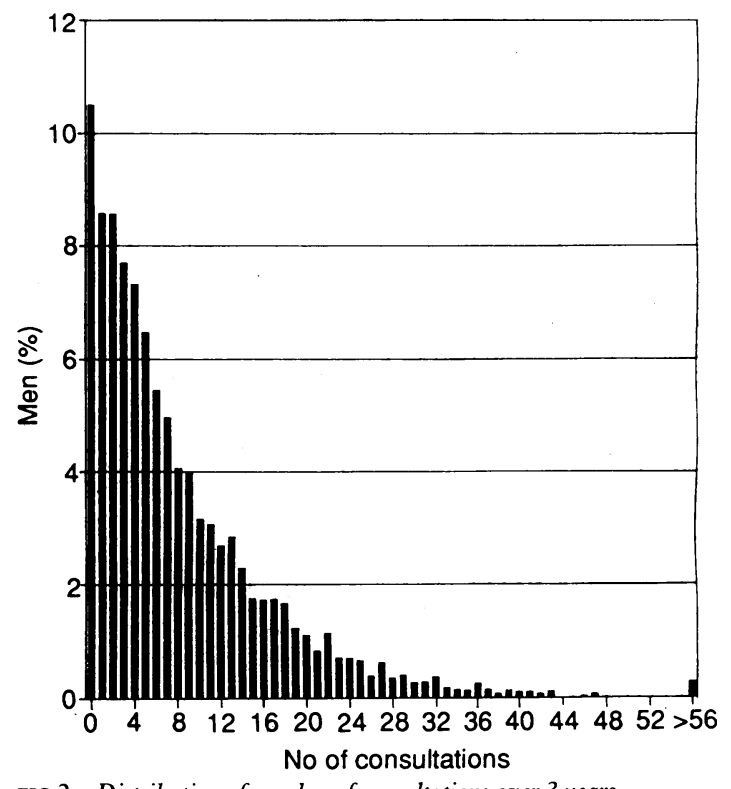

FIG 2-Distribution of number of consultations over 3 years 
TABLE III-Distribution of number of consultations over three years according to age group. Figures are numbers (percentages) of men

No of consultations over three years

\begin{tabular}{lccccc} 
& No of men & \multicolumn{1}{c}{0} & $1-6$ & $7-18$ & $\geqslant 19$ \\
\cline { 3 - 6 } Age & 1747 & $200(11 \cdot 4)$ & $902(51 \cdot 6)$ & $516(29 \cdot 5)$ & $129(7 \cdot 4)$ \\
$46-$ & 1775 & $204(11 \cdot 5)$ & $826(46 \cdot 5)$ & $563(31 \cdot 7)$ & $182(10 \cdot 3)$ \\
$51-$ & 1798 & $173(9 \cdot 6)$ & $738(41 \cdot 0)$ & $651(36 \cdot 2)$ & $236(13 \cdot 1)$ \\
$56-$ & 1693 & $159(9 \cdot 4)$ & $628(37 \cdot 1)$ & $655(38 \cdot 7)$ & $251(14 \cdot 8)$ \\
$61-$ & 7013 & $736(10 \cdot 5)$ & $3094(44 \cdot 1)$ & $2385(34 \cdot 0)$ & $798(11 \cdot 4)$ \\
\hline Total & & & & &
\end{tabular}

TABLE IV-Distribution of number of consultations over three years according to social class. Figures are numbers (percentages) of men

\begin{tabular}{lccccc}
\hline & & \multicolumn{4}{c}{ No of consultations over three years } \\
\cline { 3 - 6 } Social class & No of men & 0 & $1-6$ & $7-18$ & $\geqslant 19$ \\
\hline I & 557 & $86(15 \cdot 4)$ & $280(50 \cdot 3)$ & $156(28 \cdot 0)$ & $35(6 \cdot 3)$ \\
II & 1604 & $148(9 \cdot 2)$ & $766(47 \cdot 8)$ & $541(33 \cdot 7)$ & $149(9 \cdot 3)$ \\
III (Non-manual) & 648 & $64(9 \cdot 9)$ & $289(44 \cdot 6)$ & $231(35 \cdot 6)$ & $64(9 \cdot 9)$ \\
III (Manual) & 3018 & $316(10 \cdot 5)$ & $1259(41 \cdot 7)$ & $1036(34 \cdot 3)$ & $407(13 \cdot 5)$ \\
IV & 695 & $67(9 \cdot 6)$ & $299(43 \cdot 0)$ & $254(36 \cdot 5)$ & $75(10 \cdot 8)$ \\
V & 279 & $34(12 \cdot 2)$ & $106(38 \cdot 0)$ & $94(33 \cdot 7)$ & $45(16 \cdot 1)$ \\
\hline Total & 6801 & $715(10 \cdot 5)$ & $2999(44 \cdot 1)$ & $2312(34 \cdot 0)$ & $775(11 \cdot 4)$ \\
\hline
\end{tabular}

${ }^{\star} 16$ Men whose longest occupation was in the armed services have been excluded.

TABLE V-Comparison of number of consultations a year for men in Royal College of General Practitioners' morbidity survey and British regional heart study (year 8). Figures are percentages (numbers) of men

\begin{tabular}{lcc}
\hline $\begin{array}{l}\text { No of consultations } \\
\text { a year }\end{array}$ & Morbidity survey & Regional heart study \\
\hline 0 & $38 \cdot 8(11419)$ & $28 \cdot 4(1993)$ \\
1,2 & $25 \cdot 5(7492)$ & $31 \cdot 1(2183)$ \\
$3-6$ & $21 \cdot 5(6326)$ & $26 \cdot 6(1864)$ \\
$\geqslant 7$ & $14 \cdot 2(4184)$ & $13 \cdot 9(973)$ \\
\hline Total & $100 \cdot 0(29421)$ & $100 \cdot 0(7013)$ \\
\hline
\end{tabular}

$7 \cdot 7,8 \cdot 1,9 \cdot 1,8 \cdot 5$, and $10 \cdot 0$ for the six social classes. This averaging concealed the finding that the proportion of men not seen over three years was unrelated to social class (table IV; $\chi^{2}$ for trend $=1 \cdot 08, p=0 \cdot 3$ ). At the other extreme the proportion of heavy consulters rose from $6 \cdot 3 \%$ in social class $I$ to $16 \cdot 1 \%$ in social class $V\left(\chi^{2}\right.$ for trend $=30 \cdot 27, \mathrm{p}<0 \cdot 0001$ ).

VARIABILITY IN CONSULTATION RATES BETWEEN PRACTICES

The estimated proportion of men not consulting over three years varied from $7 \cdot 7 \%(20 / 259)$ in one practice to $13 \cdot 2 \%(42 / 317)$ in another. These estimates will differ from the true proportions of non-consulters as only a proportion of men in each practice in the relevant age range was sampled. A $\chi^{2}$ test for heterogeneity provided no evidence that the true proportion of non-consulters varied among practices $(p=0.85)$. In contrast, the proportion of men consulting more than 18 times over the three years varied far more than might be attributed to chance: from $6.0 \%(15 / 250)$ in one practice to $21.5 \%(65 / 302)$ in another $(p<<0.001)$.

\section{Discussion}

We have shown that the mean is not an appropriate summary measure of consultation rates and may conceal important differences among practices or other groups. Though mean consultation rates rose with age and were higher in manual than non-manual workers, the proportion of men not consulting over three years was about $10 \%$ at all ages and in all social classes. There was no evidence that the proportion of non-consulters varied among practices.

The new general practitioner's contract stipulates that all patients aged 16-74 must be provided with a consultation to promote health and prevent illness at least once every three years. ${ }^{1}$ Of the $31.5 \%$ of men not seen in year 6 in our study, two thirds were seen over the next two years, reducing the proportion who needed a special invitation to $10 \cdot 5 \%$. Thus our data suggest that most practices will have to approach a tenth of their male patients aged 46-65 specially to provide this service even if contact with those consulting at least once is regarded as sufficient for this service.

Clearly such data are needed for all ages and both sexes. Data from the Royal College of General Practitioners' morbidity survey, ${ }^{2}$ which relate to only one year, emphasise that the proportion of non-consulters does vary by age when women or a wider age range are studied, being highest for men aged $15-44$ (45\% did not consult over one year) and lowest for infants (16\%), women of childbearing age $(27 \%)$, and the elderly $(26 \%)$. The only published data on patterns of attendance in general practice over three years that we have traced reported that a tenth of patients were not seen over that period. ${ }^{6}$ These data were for a new practice in Livingston, a new town in central Scotland, and were for all ages and both sexes combined. Other published data relate almost entirely to shorter periods. As we found, it is not possible to predict consultation rates (and in particular the proportion of non-consulters) over three years from one year's data unless the correlation of consultation patterns from one year to the next is known.

The main sources of data on consultation rates in general practice are the general household survey ${ }^{3}$ and the Royal College of General Practitioners' morbidity survey. ${ }^{2}$ Comparison of our data with data from these sources is difficult. Each study uses a different sampling frame (though the regional heart study and the morbidity survey are both based on general practice lists), and the data from the regional heart study and general household survey incorporate bias due to non-response, though this should not be a major problem by year 8 of the regional heart study. Equally important is that each study uses a slightly different definition of a consultation: in the British regional heart study a consultation is defined as any recording in medical notes with a date; in the general household survey consultations are defined as any "consultations with NHS general medical practitioners .... Visits to the surgery, home visits and telephone conversations are included, but contacts only with a receptionist or nurse are excluded"; and in the morbidity survey a consultation is "Any face to face contact between the doctor and the patient at home or at the practice premises. Advice by telephone, consultations with ancillary staff and prescriptions repeated without a consultation were not recorded."

The average consultation rate in year 8 of the British regional heart study (1986-8), when the men were 4867 , was $3 \cdot 0$. This compares with average annual consultation rates of 3.05 for men aged 45-64 in the morbidity survey (1981) and 4.0 in the general household survey (average of 1985-7). A more detailed comparison is possible with the morbidity survey (table V). Despite the identical means the proportions of both high and low consulters were lower in the British regional heart study. The lower proportion of non-consulters might be expected from the different definitions of a consultation. Other factors, however, complicate the comparison, including geographical coverage, selection of practices, and, perhaps most important, any trends in consultation rates during the 1980 s. We believe that there may have been an upward trend in consultation rates then as a result of the introduction of screening by some practices. This would show up most appreciably as a change in the proportion of non-consulters.

Finally, given the cost and other implications of inviting non-attenders to attend for screening it is worth considering the likely benefits. Several studies 
have examined elderly non-attenders and generally found them to be healthy. ${ }^{78}$ In younger people the yield of treatable disease will probably be even less but the potential for prevention is greater.

The British regional heart study is a British Heart Foundation research group. It is also supported by the Department of Health and the Chest, Heart, and Stroke Association. JKM is supported by a special project grant from the Medical Research Council.

1 Health Departments of Great Britain. General practice in the National Health Service: the 1990 contract. London: HMSO, 1989

2 Royal College of General Practitioners, Office of Population Censuses and
Surveys, Department of Health and Social Security. Morbidity statistics from general practice: third national study, 1981-2. London: HMSO, 1986:191. (Series MBS No l.)

3 Office of Population Censuses and Surveys. General household survey 1987. London: HMSO, 1989. (Series GHS No 17.)

4 Shaper AG, Pocock SJ, Walker M, Cohen NM, Wale CJ, Thompson AG. British regional heart study: cardiovascular risk factors in middle-aged men in 24 towns. Br Med f 1981;283:179-86.

5 Office of Population Censuses and Surveys. Classification of occupations. London: HMSO, 1970.

6 Freer CB, Boyle P, Ryan MP. A study of attendance patterns in general practice over three years. Health Bull 1986;44:75-80.

7 Ebrahim S, Hedley R, Sheldon M. Low levels of ill health among elderly nonconsulters in general practice. Br Med $\mathcal{f}$ 1984;289:1273-5.

8 Williams E. Characteristics of patients over 75 not seen during one year in general practice. $\mathrm{BrMed} \mathcal{f} 1984 ; 288: 119-21$.

(Accepted 14 June 1990)

\section{MEDICINE AND THE MEDIA}

BBC2 Troubleshooter.

BBC Books Troubleshooter. John Harvey-Jones with Anthea Masey

\section{Too much trouble}

The BBC is repeating the series Troubleshooter in which Sir John Harvey-Jones, one time successful managing director of ICI, is shown giving advice to ailing British businesses. But shortage of space in the television schedules means that one programme from the original series has had to be dropped. The missing programme, however, was the most fascinating - the one in which Sir John gave managerial advice to Shropshire District Health Authority. The authority certainly needed it, with a projected deficit in March 1989 of $£ 2 \mathrm{~m}$ in a total budget of $£ 80 \mathrm{~m}$ and a waiting list of 8000 and growing.

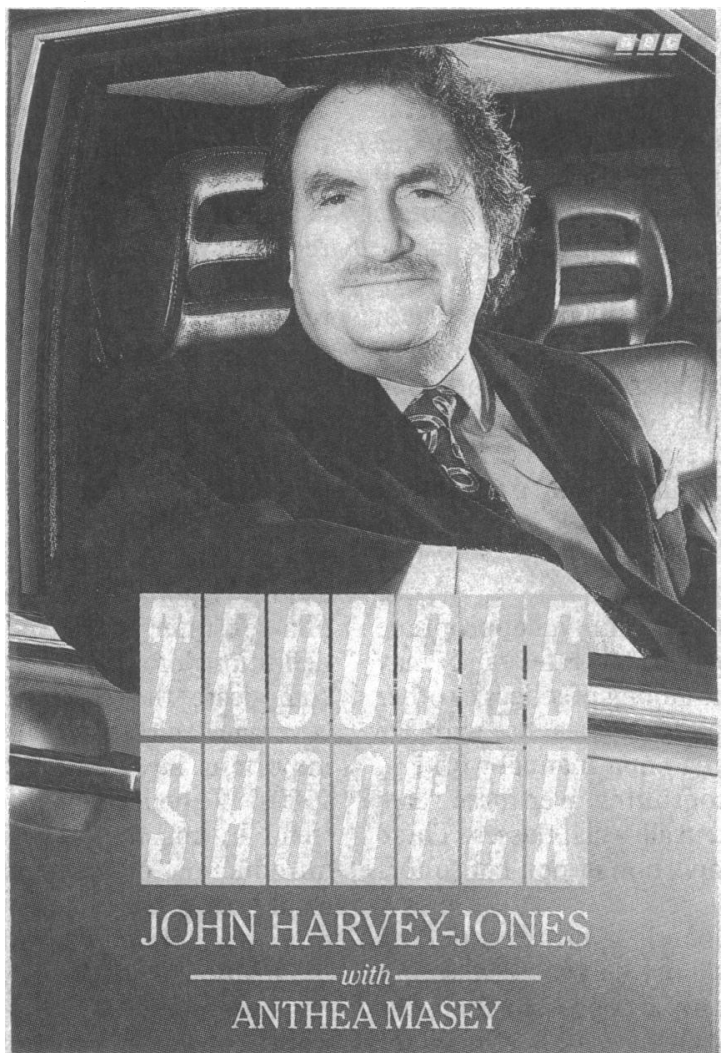

All is not lost for those who missed the programmethe health authority's tale of woe can be found in the book of the series (BBC Books 1990, £12.95.) Describing Sir John's assignment as formidable, the blurb asks "how do you manage an organisation upon which people's lives depend within the constraints of a tight fixed budget?" With great difficulty, it seems.

In the programme the district general manager, Ken Morris, was introduced as having passed up professional football to take a job in the civil service. Sir John, looking disconcertingly like the actor Leo McKern, went on a tour of the district, on visits to district health authority meetings, and on a fact finding mission to the regional health authority. With these insights, he described Ken as being "between the upper and lower grindstones" (the region above and the district health authority below).

One of the problems was clearly that the members of the district health authority, speaking with the voice of the patients (Sir John referred to them as customers), disliked Ken's plans for closing cottage hospitals. Showing not a little disdain for anything resembling democracy, the district chairman, self made millionaire Frank Jones, suggested sacking the lot of them.

Throughout the programme the NHS appeared a lumbering leviathan, which in its efforts to be generally fair and democratic was ending up pointing in no particular direction, and with many of its workforce uncertain of what strategy was being followed. Ken managed to smile through it all, including through Sir John's brutal but kindly delivered parting remarks that he did not expect Ken to be around for very long unless he could be seen to be managing more positively.

Sir John gave a few interim thoughts on the white paper, particularly that cottage hospitals might do well in a mixed economy. His visit to Shrewsbury General Hospital, on the other hand, obviously appalled him and he could make no suggestions other than more money and "sharper management," whatever that is. It was while he toured the outlying wards in dilapidated Nissen huts, dating from the second world war that the enormity of the NHS's problems seemed to strike home.

By the end of the programme Ken had resigned to join the private sector and Frank had retired. Sir John was quite clear on two things, the first being that the white paper will be a good thing if it simplifies the health authorities but only if there are managers of the very highest calibre. Managers of that calibre cost money, real money $-£ 200000$ a year. Sir John won't be in the running, though, because the second thing on which he was quite clear was that he wouldn't want a job as a district general manager in the NHS. NEVILLE W GOODMAN, consultant senior lecturer in anaesthesia, University of Bristol, Bristol 